\title{
DUKUNGAN KELUARGA DAN MASYARAKAT TERHADAP KONSEP DIRI SISWA TUNAGRAHITA
}

\author{
Magdalena Praharani Kelen ${ }^{1}$, Jesika Pasaribu² \\ ${ }^{1}$ Mahasiswa Sekolah Tinggi Ilmu Kesehatan Sint Carolus \\ ${ }^{2}$ Dosen Sekolah Tinggi Ilmu Kesehatan Sint Carolus \\ pasariboe.jesika@gmail.com
}

\begin{abstract}
Abstrak
Keluarga dan masyarakat belum paham mengenai kecacatan yang dialami oleh siswa tunagrahita sehingga terdapat stigma bahwa siswa tunagrahita sebagai orang cacat yang tidak bisa mandiri dan memiliki kemampuan intelektual rendah. Stigma tersebut dapat mempengaruhi persepsi siswa tunagrahita terhadap konsep diri mereka sehingga cenderung negatif. Penelitian kuantitatif non-eksperimental dengan desain deskriptif korelasi bertujuan untuk mengetahui adanya hubungan dukungan keluarga dan masyarakat terhadap konsep diri siswa tunagrahita di SLBN Kupang. Populasi pada penelitian ini adalah seluruh siswa tunagrahita di SLBN Kupang. Sampel diperoleh secara accidental sampling sebanyak 84 responden. Pengambilan data dilakukan melalui pengisian kuesioner konsep diri, dukungan keluarga dan dukungan masyarakat. Hasil penelitian ditemukan terdapat konsep diri positif 52,4\%, dukungan keluarga $52,4 \%$ dan dukungan masyarakat (53,6 ). Hipotesis di uji menggunakan uji Chi-square; sbb: tidak ada hubungan yang bermakna antara dukungan orang tua terhadap konsep diri ( $\mathrm{p}$ value $=0,197$ ) dan tidak ada hubungan bermana antara dukungan masyarakat terhadap konsep diri ( $\mathrm{p}$ value $=0,389$ ). Hasil penelitian menunjukkan perlunya dukungan keluarga dan masyarakat agar penyandang tunagrahita tetap memiliki konsep diri yang positif.
\end{abstract}

Kata kunci: Tunagrahita, konsep diri, dukungan keluarga, dukungan masyarakat

\begin{abstract}
The relationship of Family and Sosial Support with self-concept of intellectual disability students's. In common, families and communities do not understand well the disability experienced by intellectual disability students. This arises a stigma that intellectual disability students are disabled people who cannot be independent and have low intellectual abilities. This stigma may affect the perception of intellectual disability students on their self-concept that tend to be negative. The purpose of this study was to determine the relationship of Family and Sosial Support with self-concept of intellectual disability students's in SLBN Kupang NTT 2016. This research method was non-experimental quantitative research with descriptive correlation design. The population in this study were all intellectual disability students in SLBN Kupang. The sample was obtained by accidental sampling of 84 respondents. Data collection is done through filling out self-concept questionnaires, family support and community support. The results of the study found $52.4 \%$ positive self-concept, 52.4\% family support and social support (53.6). The hypothesis was tested using the Chi-square test: there is no significant relationship between parental support for self-concept ( $\mathrm{p}$ value $=0.197$ ) and no significant relationship between community support for self-concept ( $p$ value $=0.389$ ). The results of the study indicate the need for family and social support to improve positive self-concept of intellectual disability students .
\end{abstract}

Keywords: Intellectual disability, self-concept, family support, social support

\section{Pendahuluan}

Tunagrahita dijelaskan sebagai fungsi intelektual umum yang berada sangat dibawah rata-rata sehingga dapat menyebabkan atau disertai dengan gangguan perilaku adaptif yang sudah terlihat selama masa tumbuh kembang seorang anak sebelum mencapai usia 18 tahun (Sadock, 2013). Anak yang dilahirkan dalam keadaan normal seperti halnya siswa tunagrahita, mengalami keterbelakangan mental atau dikenal dengan retardasi mental. Dunia pendidikan mengenalnya dengan istilah tunagrahita (Rochyadi, 2012). Berdasarkan kecacatan yang dialami oleh tunagrahita maka American Assosiation On Mental Deficiency (AAMD) mengklasifikasikan tunagrahita dalam tiga derajat kecacatan yaitu; tunagrahita ringan (debil), tunagrahita sedang atau moderate (imbisil) dan tunagrahita berat (idiot). 
World Health Organization (WHO) memperkirakan prevelensi keseluruhan anak tunagrahita di dunia sebesar 1-3\% telah dirujuk ke ahli saraf dan sebanyak 0,5-2,5\% dari prevelensi anak yang dirujuk tersebut berada dalam klasifikasi ringan sampai berat. Di Indonesia belum ada gambaran pasti mengenai jumlah siswa tunagrahita, tetapi berdasarkan data dari Buletin Jendela Data dan Informasi Kesehatan Semester II tahun 2014, menyebutkan ada sekitar 30.460 anak tunagrahita di Indonesia.

Kementerian Pendidikan Nasional Indonesia dalam data Kementerian Kesehatan Republik Indonesia (2014) menyebutkan sebanyak 4.253 orang siswa tunagrahita sedang bersekolah di 108 Sekolah Luar Biasa (SLB C) khusus tunagrahita yang tersebar di seluruh Indonesia. Data Direktorat Pendidikan Sekolah Luar Biasa (PSLB) menyebutkan pada tahun ajaran 2015/2016 ada sekitar 1.153 siswa tunagrahita sedang menempuh pendidikan di SLB yang ada provinsi Nusa Tenggara Timur (NTT).

Siswa tunagrahita sering mengalami diskriminasi karena masalah keterbelakangan mental, tidak jarang mereka ditolak oleh orang terdekat seperti orang tua dan keluarga, lingkungan masyarakat dan teman-teman sebaya terutama yang tidak sekolah di SLB (Sadrossat \& Moghaddmi, 2010). Penolakan dan diskriminasi ini sangat memengaruhi konsep diri mereka karena mereka akan tumbuh dalam konsep diri yang negatif sebagai orang cacat (Dulisanti, 2015).

Konsep diri merupakan hasil penilaian orang lain atau individu terhadap dirinya sendiri dan berkaitan erat dengan perilaku, budaya serta lingkungan (Stuart, 2016). Menurut Brown \& Schormans, (2014) siswa tunagrahita memiliki kualitas hidup yang buruk. Siswa tunagrahita sering mengalami isolasi sosial dalam lingkungan masyarakat sehingga kurang mendapat kesempatan untuk mengembangkan kemampuan sosialisasi.
Di Indonesia, masyarakat belum paham mengenai kecacatan yang dialami oleh siswa tunagrahita sehingga stigma diberikan masyarakat yang menganggap bahwa siswa tunagrahita sebagai orang cacat yang tidak bisa mandiri, bodoh dan memiliki kemampuan intelektual rendah. Persepsi masyarakat terhadap siswa tunagrahita ini turut mempengaruhi konsep diri mereka menjadi negatif karena menyebabkan mereka menjadi kurang percaya diri (Jamilah, 2007).

Kecacatan yang dialami oleh siswa itunagrahita menyebabkan mereka berbeda dengan siswa itunagrahita disekolah reguler. Hal ini terlihat pada kemampuan perkembangan bahasa yang lambat, keterbatasan dalam berhitung, tidak mampu bertanggung jawab dengan diri sendiri, dan perilaku agresif yang cenderung mengganggu orang lain terutama teman sebaya. Perilaku ini menyebabkan siswa tunagrahita kurang diterima dalam lingkungan teman sebaya. Siswa tunagrahita perlu berinteraksi dengan lingkungan sosial untuk mengembangkan kepribadian mereka (Sadrossat \& Moghaddmi, 2010).

Kecacatan yang dialami oleh siswa tunagrahita menyebabkan mereka mengalami diskriminasi dalam masyarakat, hal ini terlihat di beberapa negara di Asia dimana penyandang disabilitas termasuk siswa tunagrahita masih mendapatkan perlakuan yang tidak manusiawi (Gupta \& Mathur, 2012).

Siswa tunagrahita sama seperti pelajar pada umumnya-tetap membutuhkan pendidikan untuk mengembangkan bakat dan kemampuan namun dengan sistem pendidikan yang berbeda dengan pelajar pada umumnya. Sistem pendidikan tunagrahita lebih menekankan pada kemampuan motorik dan keterampilan praktis karena rendahnya tingkat intelegensi yang dimiliki. Siswa tunagrahita bersekolah di SLB atau pendidikan inklusi (Rochyadi, 2012). 
SLBN Kupang dalam tahun ajaran 2016/2017 memiliki 84 orang siswa tunagrahita dari jenjang pendidikan Sekolah Dasar (SD), Sekolah Menengah Pertama (SMP) dan Sekolah Menengah Atas (SMA) (Data SLBN Kupang, 2016). Hasil wawancara dengan guru di SLBN Kupang, siswa tunagrahita di SLBN Kupang, tempat yang akan dijadikan lahan penelitian memiliki prestasi yang cukup membanggakan dimana setiap tahunnya mereka terjadwal mengikuti perlombaan olahraga tingkat daerah, nasional maupun tingkat dunia khusus bagi tunagrahita. Tidak sebatas berpartisipasi tetapi mereka sering menjuarai perlombaan tersebut, bahkan beberapa siswa mereka menjadi atlet nasional khusus penyandang disabilitas.

Tujuan penelitian ini secara umum adalah agar diketahuinya hubungan dukungan keluarga dan masyarakat dengan konsep diri siswa tunagrahita di SLBN Kupang Nusa Tenggara Timur tahun 2016. Tujuan khusus dilakukan penelitian ini adalah untuk mengetahui gambaran karakteristik siswa tunagrahita, hubungan antara dukungan keluarga dan masyarakat terhadap konsep diri siswa tunagrahita di SLBN Kupang Nusa Tenggara Timur tahun 2016.

\section{Metode}

Penelitian ini menggunakan metode kuantitatif non eksperimental, desain penelitian deskriptif korelasi terhadap responden tentang hubungan konsep diri siswa tunagrahita di SLBN Kupang NTT dengan dukungan keluarga dan masyarakat. Variabel bebas dalam penelitian ini adalah dukungan keluarga dan masyarakat sedangkan variabel terikat adalah konsep diri siswa tunagrahita di SLBN Kupang NTT.

Populasi dalam penelitian ini adalah seluruh siswa/i tunagrahita di SLBN
Kupang NTT. Populasi penelitian adalah seluruh siswa di SLBN Kupang yakni 84 orang. Sampel penelitian ditentukan secara total sampling yakni sebanyak 84 responden. Penelitian telah dilakukan di SLBN Kupang Nusa Tenggara Timur pada bulan Agustus 2016.

Instrumen pengumpulan data terdiri dari kuesioner konsep diri siswa tunagrahita, dukungan keluarga dan dukungan masyarakat. Pengisian kuesioner dilakukan sendiri oleh responden namun didampingi oleh guru. Kuesioner telah dilakukan uji validitas dan realibitas di SLBN 03 Kemayoran Jakarta. Tata bahasa pada kuesioner disusun dengan bahasa telah disederhanakan agar dapat dipahami para responden. Etika penelitian yang diterapkan yakni azas manfaat, menghormati martabat, adil, dan kerahasiaan responden.

Teknik analisis data menggunakan analisis univariat dan bivariat. Analisis bivariat dilakukan untuk mengetahui hubungan antara variabel independen dan variabel dependen. Analisis bivariat menggunakan uji statistik Chi-Square dengan tingkat kemaknaan $(\alpha) 5 \%=0,05$. Jika nilai $\mathrm{p}<0,05$ maka Ha diterima artinya terdapat hubungan antara variabel independen dan dependen. Jika nilai $\mathrm{p}>$ 0,05, maka Ha ditolak artinya tidak ada hubungan antara variabel independen dan variabel dependen.

\section{Hasil}

Karkteristik responden disajikan pada tabel 1. Hubungan dukungan keluarga dengan konsep diri siswa tunagrahita disajikan pada tabel 2. Sedangkan Hubungan dukungan lingkungan dengan konsep diri siswa tunagrahita disajikan pada tabel 3 . 
Tabel 1.

Karakteristik responden $(\mathrm{n}=84)$

\begin{tabular}{lcc}
\hline \multicolumn{1}{c}{ Karakteristik } & f & $\%$ \\
\hline Jenis kelamin & 53 & 63,1 \\
\hline Laki-laki & 31 & 36,9 \\
\hline Perempuan & & \\
\hline Usia & 17 & 20,3 \\
\hline $8-12$ tahun & 39 & 46,4 \\
\hline $13-16$ tahun & 28 & 33,3 \\
\hline $17-21$ tahun & & 33,3 \\
\hline Tingkat pendidikan & 28 & 25 \\
\hline SD & 21 & 41,7 \\
\hline SMP & 35 & 52,4 \\
\hline SMA & & 47,6 \\
\hline Konsep Diri & 44 & \\
\hline Konsep diri positif & 40 & 47,6 \\
\hline Konsep diri negative & & \\
\hline Dukungan orang tua & 44 & 46,6 \\
\hline Mendukung & 40 & \\
\hline Tidak mendukung & & \\
\hline Dukungan Lingkungan & 45 & \\
\hline Mendukung & 39 & \\
\hline Tidak mendukung & & \\
\hline
\end{tabular}

Tabel 2.

Hubungan dukungan keluarga dengan konsep diri siswa tunagrahita (n:84)

\begin{tabular}{|c|c|c|c|c|c|c|c|}
\hline \multirow{3}{*}{ Dukungan keluarga } & \multicolumn{4}{|c|}{ Konsep Diri } & \multirow{2}{*}{\multicolumn{2}{|c|}{ Total }} & \multirow[t]{3}{*}{$\mathrm{p}$ value } \\
\hline & \multicolumn{2}{|c|}{ Positif } & \multicolumn{2}{|c|}{ Negatif } & & & \\
\hline & $\mathrm{f}$ & $\%$ & $f$ & $\%$ & $\mathrm{f}$ & $\%$ & \\
\hline Mendukung & 26 & 59,1 & 18 & 40,9 & 44 & 100 & 0,197 \\
\hline Tidak mendukung & 18 & 45 & 22 & 55 & 40 & 100 & \\
\hline Total & 44 & 52,4 & 40 & 47,6 & 84 & 100 & \\
\hline
\end{tabular}

Tabel 3.

Hubungan dukungan lingkungan dengan konsep diri siswa tunagrahita (n:84)

\begin{tabular}{cccccccc}
\hline \multirow{2}{*}{ Dukungan lingkungan } & \multicolumn{4}{c}{ Konsep Diri } & \multirow{2}{*}{ Total } & \multirow{2}{*}{$\mathrm{p}$ value } \\
\cline { 2 - 6 } & \multicolumn{2}{c}{ Positif } & Negatif & & \\
\cline { 2 - 6 } & $\mathrm{f}$ & $\%$ & $\mathrm{f}$ & $\%$ & $\mathrm{f}$ & $\%$ & \multirow{2}{*}{0,389} \\
\hline Mendukung & 26 & 59,1 & 19 & 47,5 & 45 & 100 & \\
\hline Tidak mendukung & 18 & 40,9 & 21 & 52,5 & 39 & 100 \\
\hline Total & 44 & 52,4 & 40 & 47,6 & 84 & 100 & \\
\hline
\end{tabular}

\section{Pembahasan}

Pada tabel 1 menunjukkan bahwa responden berjenis kelamin laki-laki sebesar $63,1 \%$. Hal ini menunjukan bahwa mayoritas siswa di SLBN Kupang NTT tahun 2016 berjenis kelamin laki-laki.
Sebaran usia responden terbanyak pada usia 13-16 tahun (46,4\%). Data dari sekolah didapatkan sebagian besar murid mereka merupakan pindahan dari sekolah biasa (SD) karena siswa sering mengulang kelas lebih dari 3 kali. Terlambatnya 
deteksi awal dan kesiapan mental orang tua yang kurang membuat para siswa harus mengulang di sekolah biasa, sehingga berdampak pada usia sekolah mereka. Pengabaian dari orang tua dan keluarga mempengaruhi deteksi dini terhadap kecacatan siswa tunagrahita sehingga berdampak pada usia sekolah siswa tunagrahita (Rashid,2012).

Jumlah murid terbanyak pada tingkat pendidikan SMA (41,7\%). Data ini diasumsikan bahwa semakin tingginya kesadaran masyarakat terutama orang tua yang memiliki anak penyandang disabilitas untuk menyekolahkan anak mereka ke jenjang pendidikan yang lebih tinggi. Tersedianya sarana dan prasarana yang cukup lengkap menjadi salah satu pertimbangan orang tua anak penyandang disabilitas untuk menyekolahkan anak mereka di SLBN Kupang.

Sebanyak $52,4 \%$ siswa memiliki konsep diri positif dan sebanyak 47,6\% siswa memiliki konsep diri negatif. Hasil penelitian menjelaskan sebagian besar responden mengakui bahwa mereka merasa berbeda dengan teman-teman mereka yang sekolah di sekolah biasa karena kecacatan yang dialami.

Sebanyak 52,4\% keluarga memberikan dukungan kepada anak tunagrahita kepada siswa tunagrahita. Keterbatasan sosial ekonomi dan budaya mempengaruhi dukungan orang tua dan keluarga SLBN Kupang, 2016). Zuna \& Brown (2014) menyatakan bahwa keluarga yang memiliki anak tunagrahita membutuhkan dukungan berupa informasi dan keuangan karena merawat anak dengan kecacatan intelektual seperti siswa tunagrahita membutuhkan biaya lebih. Siswa tunagrahita membutuhkan biaya tambahan untuk perawatan dan pengobatan mereka.

Terdapat sebanyak $53,6 \%$ siswa tunagrahita mendapatkan dukungan dari masyarakat. Penelitian Vaz, Cordier, Flakmer, Ciccarelli, Parsons, etc (2015) menyatakan kecacatan bukan hanya satusatunya yang mempengaruhi dukungan sosial tetapi partisipasi aktif sangat mempengaruhi dukungan masyarakat terhadap siswa tunagrahita. Interaksi dan keterlibatan aktif mereka di lingkungan membuat mereka semakin dikenal oleh lingkungan masyarakat.

Sekolah-sekolah di Kupang sudah mulai menerapkan pendidikan inklusi sehingga memungkinkan siswa penyandang disabilitas seperti tunagrahita bisa mengikuti pendidikan di sekolah biasa. Meskipun berteman dengan siswa yang tidak sekolah di SLB siswa tunagrahita masih merasa canggung karena adanya label sebagai anak cacat yang diberikan kepada mereka. Masih ada stigma terhadap siswa tunagrahita, namun pada dasarnya teman sebaya menerima keberadaan mereka di lingkungan sekolah tetapi tidak sepenuhnya (Dulisanti, 2015). Di sekolah inklusi teman-teman sebaya yang normal memberikan pengaruh dan dukungan yang signifikan terhadap siswa tunagrahita (Yeniarti \& Mahmuda, 2015).

Sebanyak $59,1 \%$ siswa tunagrahita mendapat dukungan keluarga memiliki konsep diri positif, namun 40,9\% memiliki konsep diri negatif walau keluarga mendukung. Hasil uji ChiSquare didapatkan $p$ value $=0,197$ (> $0,05)$ berarti tidak ada hubungan yang bermakna antara dukungan keluarga dengan konsep diri siswa tunagrahita di SLBN Kupang.

Penelitian Sulistyarini dan Saputra (2015) menemukan bahwa keluarga belum memberikan dukungan yang maksimal terhadap siswa tunagrahita sehingga mereka tumbuh dalam konsep diri yang negatif. Berbagai perilaku terhadap penderita tunagrahita beragam, seperti penolakan, malu atau rasa bersalah. Saban \& Arikan (2011) menemukan pada risetnya bahwa $68,5 \%$ sibling memiliki ketakutan bahwa suatu saat mereka juga akan mengalami hal yang sama; 77,8 \% melaporkan malu karena memiliki saudara yang mengalami tunagrahita.

$$
\text { Penelitian Onshton }
$$
menjelaskan bahwa peranan orang tua 
sangat penting terhadap pembentukan konsep diri seorang penyandang tunagrahita. Deteksi dan penanganan yang tepat dari orang tua dan keluarga sangat membantu penyandang tunagrahita. Namun kebanyakan orang tua terlambat menyadari masalah yang dialami oleh siswa/i, sehingga orang tua atau keluarga memberikan respon awal yang kurang baik atau negatif.

Selanjutnya Onshton menjelaskan, awalnya orang tua akan membandingkan siswa/i tunagrahita dengan saudara mereka yang normal. Orang tua akan terus memotivasi bahkan memaksa siswa/itunagrahita untuk tetap bersekolah di sekolah biasa sehingga sekolah dapat menjadi salah satu tempat deteksi masalah kecacatan intelektual siswa/i tunagrahita. Hal ini sejalan dengan Saddocks (2013), menjelaskan karakteristik anak tanagrahita adalah kecacatan intelektual akan terlihat selama masa tumbuh kembang dan jarang terlihat adanya kecacatan fisik. Inilah yang menyebabkan orang tua kurang menyadari masalah kecacatan yang dialami siswa/i tunagrahita.

$$
\text { Selain berdampak pada }
$$
perkembangan keluarga, adanya seseorang dengan tunagrahita dirumah juga akan memengaruhi kualitas hubungan penderita dengan anggota keluarga lainnya. Lafferty, O'Sullivan, O'Mahoney, et al (2016) menyatakan bahwa keluarga yang memiliki anggota keluarga yang mengalami tunagrahita cenderung memiliki tingkat ketahanan (relisiens) yang rendah dibandingkan dengan populasi. Timbulnya konflik pada keluarga sangat mungkin terjadi akibat beban yang dirasakan keluarga saat merawat penderita tunagrahita dirumah. Ketahanan keluarga yang rendah-bagaikan lingkaran-akan membuat ketahanan penderita tunagrahita juga rendah. Kondisi ini berpotensi menumbuhkan kerentanan bagi penderita tunagrahita.

Kualitas hidup keluarga turut mempengaruhi kualitas hidup anak yang mengalami kecacatan intelektual seperti tunagrahita. Keluarga yang memiliki anak tunagrahita kemungkinan besar mengalami tingkat stress yang cukup tinggi sehingga berdampak pada pola asuh mereka terhadap anak tunagrahita. Pola asuh keluarga yang baik membantu anak tunagrahita tumbuh dalam konsep diri yang positif dan sebaliknya pola asuh yang kurang baik menyebabkan anak tunagrahita tumbuh membentuk konsep diri yang kurang baik karena anak tumbuh dalam stigma sebagai anak cacat yang tidak mampu mandiri (Zuna \& Brown, 2014).

Sejalan dengan ulasan Rochyadhi (2012), siswa tunagrahita kurang mampu memahami kelebihan dan kekurangan mereka sehingga turut mempengaruhi konsep diri mereka. Siswa tunagrahita kurang mampu menilai kelebihan dan kekurangan dalam diri mereka sehingga butuh dukungan dari orang tua dan keluarga, lingkungan maupun temanteman sebaya.

Siswi tunagrahita yang memiliki konsep diri rendah akan mengalami kendala pada aktivitas akademik dan juga area social. Akibatnya siswa akan menjadi lebih rentan karena tidak memiliki kelebihan dan kemampuan hidup dalam masyarakat. Kegagalan ini dapat menimbulkan ketidakberdayaan, frustasi sehingga menjadi predisposisi munculnya ansietas pada kehidupan social dimasa mendatang.

Tri (2015) menjelaskan rasa percaya diri siswa tunagrahita mempengaruhi konsep diri mereka menjadi positif. Rasa percaya diri mendorong siswa tunagrahita untuk berinteraraksi dengan dunia luar. Keluarga dan guru-guru di lingkungan sekolah sedianya membantu siswa tunagrahita mendapatkan rasa percaya diri yang lebih

Pada tabel 3 ditemukan sebesar $59,1 \%$ responden mendapat dukungan lingkungan dan konsep diri positif. Sedangkan $40,9 \%$ responden yang tidak mendapatkan dukungan dari lingkungan 
namun tetap memiliki konsep diri positif. Hasil uji Chi-Square didapatkan $p$ value $=$ $0,389(>0,05)$ berarti tidak ada hubungan yang bermakna antara dukungan lingkungan dengan konsep diri siswa tunagrahita di SLBN Kupang.

Penelitian ini sejalan dengan penelitian Paterson, McKenzie \& Lindsay (2012) bahwa tidak ditemukan adanya hubungan yang bermakna antara stigma masyarakat terhadap konsep diri negatif penyandang tunagrahita di Amerika. Pada beberapa penelitian terkait sebelumnya dijelaskan bahwa besarnya stigma yang diberikan kepada penyandang tunagrahita berhubungan dengan rendahnya konsep diri dan cenderung mengalami konsep diri yang negatif.

Masyarakat turut mempunyai andil dalam membentuk konsep diri tunagrahita. Pelebelan atau stigma terhadap siswa tunagrahita berasal dari masyarakat. Masih ada masyarakat yang memberikan stigma negatif terhadap siswa tunagrahita. Hal ini sejalan dengan data yang peneliti temukan di lapangan, responden mengaku bahwa mereka turut berpartisipasi dalam kegiatan lingkungan. Menurut peneliti selain masalah intelektual, label sebagai penyandang disabilitas turut mempengaruhi peranan responden dalam lingkungan yang akhirnya mempengaruhi konsep diri mereka.

Penelitian Kenyon \& Jackson (2014), terhadap 10 responden penyandang tunagrahita dengan menggunakan pendekatan fenomenologis interpretative mendapatkan hasil adanya pelebelan terhadap penyandang tunagrahita terlebih dahulu mempengaruhi pembentukan konsep mereka. Berdasarkan hasil wawancara, responden mengakui mereka merasa ragu dan minder untuk mulai berinteraksi dengan lingkungan sosial karena takut diberi lebel penyandang cacat. Hal ini dapat membentuk konsep diri tunagrahita menjadi negatif.

Pijl \& Skaalvik (2010) mengulas dari penelitiannya tentang siswa/i tunagrahita dengan kelompok teman sebaya menjelaskan siswa/i tunagrahita beresiko tinggi mengalami isolasi sosial dari teman sebaya karena masalah kecacatan intelektual. Penyandang tunagrahita mengalami diskriminasi dan penolakan menyebabkan siswa tunagrahita mengalami kesepian dan menjadi rendah diri. Rasa kesepian dan dan rendah diri menyebabkan siswa/i tunagrahita memiliki konsep diri yang negatif. Perilaku penyandang tunagrahita yang kurang aktif secara social mengakibatkan siswa/i tunagrahita memiliki teman lebih sedikit dibandingkan dengan siswa yang tidak sekolah di SLB.

Penelitian kualitatif yang dilakukan oleh Dulisanti (2015), mengenai studi kasus pada proses pendidikan inklusif di SMK Negeri 2 Malang mendapatkan hasil stigma yang diberikan kepada siswa/i tunagrahita adalah stigma menghambat, memiliki nilai jelek, serta kurang bisa bergaul.Selain itu juga diskriminasi yang dilakukan oleh teman sebaya tanpa disadari merupakan salah satu bentuk soft-bullying terhadap siswa/i tunagrahita.

Elkington, Hackler, McKinnon, Borges, Wright, et all (2012) menyatakan stigma terhadap penyandang cacat intelektual seperti tunagrahita sangat mempengaruhi konsep diri mereka. Siswa tunagrahita sudah terlanjur mendapat stigma sebagai orang cacat sehingga mereka mengalami harga diri rendah. Harga diri rendah ini mempengaruhi konsep diri mereka menjadi negatif.

Sejalan dengan penelitian Chen \& Shu (2012) yang mewawancarai siswa/i tunagrahita di sekolah menengah provinsi Taiwan Timur menjelaskan tiga hal yang mendasar dalam stigma yaitu; menjadi label, pasrah diri dan hidup dengan label yang diberikan. Label sebagai orang cacat dihasilkan dari sistem kesejahteraan sosial dan sistem pendidikan yang kurang mendukung. Ketidakberdayaan ini 
membuat siswa tunagrahita menjadi pasrah dimana pada tahap ini mereka melihat diri mereka sebagai orang cacat intelektual dan nakal. Hal ini akan menyebabkan siswa tunagrahita menerima stigma atas diri mereka dan berfikir buruk tentang diri sendiri.

Kenyon, Beail \& Jackson (2014) menyatakan pemberian stigma terhadap penyandang tunagrahita terlebih dahulu mempengaruhi pembentukan konsep mereka. Hal ini akan menyebabkan siswa tunagrahita tumbuh dengan label sebagai orang cacat intelektual. Stigma buruk menimbulkan kompensasi negatif pada penyandang tunagrahita sehingga akhirnya mereka mengisolasikan diri dari lingkungan dan aktivitas bersama lainnya.

Pada penelitian ini, penerimaan dari masyarakat merupakan bentuk dukungan terhadap responden. Dukungan inilah membuat responden merasa diterima sehingga konsep diri mereka menjadi positif. Ataupun sebaliknya adanya penolakan atau diskriminasi membuat responden menjadi rendah diri dan mempengaruhi konsep diri mereka menjadi negatif. Segoyganya, dukungan lingkungan maupun masyarakat akan menjadi semangat dan motivasi bagi para penyandang tunagrahita.

Penelitian Yeniarti \& Mahmuda (2105), tentang pengaruh penerapan bantuan tutor sebaya terhadap anak tunagrahita di SMP Negeri 4 Gresik menjelaskan siswa/i tunagrahita cukup diterima oleh teman sebaya mereka. Penelitian dengan tekhnik "pre-test posttest" menunjukan adanya pengaruh yang signifikan antara dukungan teman sebaya yang normal terhadap teman mereka yang tunagrahita. Hal ini dibuktikan dengan hasil uji Zh 2,024 lebih besar dari nilai kritis $\alpha=5 \%$ dan tingkat kesalahan untuk 1,64 .

Gilmore \& Roberts (2013) menyatakan siswa tunagrahita lebih banyak mendapatkan dukungan dari lingkungan sekolah mereka karena adanya perasaan senasib sebagai penyandang tunagrahita sehingga membuat mereka saling mendukung. Inilah salah satu faktor yang memberi konsep diri postif untuk siswa tunagrahita.

\section{Simpulan dan Saran}

Tidak ada hubungan yang bermakna antara dukungan keluarga terhadap konsep diri siswa tunagrahita $(p$ value $=0,197$ ) dan tidak ada hubungan yang bermakna antara dukungan masyarakat terhadap konsep diri siswa tunagrahita ( $p$ value $=$ 0,389). Hasil penelitian menunjukkan perlunya dukungan keluarga dan masyarakat agar penyandang tunagrahita tetap memiliki konsep diri yang positif. Penelitian ini menggunakan penyandang tunagrahita sebagai responden sehingga dukungan keluarga dan masyarakat didapatkan dari versi responden. Penelitian ini menyarankan penelitian lanjut tentang dukungan keluarga dan masyarakat namun dari keluarga dan masyarakat itu sendiri.

\section{Daftar Pustaka}

Brown, I., \& Schormans, A. F. (2014). Quality of life, children with intellectual and developmental disabilities, and maltreatment. International Public Health Journal, 6 (2), 185-197.

Buletin Jendela Data dan Informasi Kesehatan (Semester II, 2014). Buletin Jendela dan Infomasi Kesehatan. Kementrian Kesehatan RI, hlm. 25 . http://www.depkes.go.id/download. php?file=download/pusdatin/buletin/ buletin

Chen, C., \& Shu,B. (2012). The Process Perceiving Stigmatization: Perspectives from Taiwanese Young People with Intellectual Disability. Journal of Applied Research In Intellectual Disabilities, 25 (3), 240251.

Data SLB Pembina Penfui Kota Kupang NTT, (2016). Data tidak 
dipublikasikan.Data Statistik

Sekolah Luar Biasa 2016.

Dulisanti, R. (2015). Penerimaan sosial dalam proses pendidikan inklusif (studi kasus pada proses pendidikan inklusif di SMK Negeri 2 Malang). Indonesian journal of disability studies (ijds), $2 \quad$ (1). http://ijds.ub.ac.id/index.php/ijds/art icle/download/26/18

Elkington, K. S., Hackler, D., McKinnon, K., Borges, C., Wright, E. R., \&Wainberg, M. L. (2012). Perceived mental illness stigma among youth in psychiatric outpatient treatment. Journal of Adolescent Research, 27(2), 290317.

Gupta, P. C., \&Mathur, A. (2012). Predicting the class of a mentally disabled patient to check the level of mental retardation by using feed forward back propagation neural network. International Journal of Computer Applications, 41(17).

Kenyon, E., Beail, N., \& Jackson, T. (2014). Learning disability: experience of diagnosis. British Journal of Learning Disabilities, 42(4), 257-263.

Lafferty A, O'Sullivan D, O'Mahoney P, Taggart L, van Bavel B (2016) Family carers' experiences of caring for a person with intellectual disability. Dublin: University College Dublin

Rochyadi, E., (2012). Modul Karakteristik Dan Pendidikan Anak Tunagrahita. https://scholar.google.co.id/scholar? hl=id\&q.

Tri, H. (2015). Membangun rasa percaya diri anak tunagrahita di SLB Negeri Jenangan ponorogo tahun pelajaran 2014/2015 (Doctoral dissertation,
STAIN Ponorogo)

http://etheses.stainponorogo.ac.id/10 00/1/Abstrak,\%20BA B\%20I-II.pdf

Jamilah. K. A., (2007). Special Education For Special Children; Panduan Khusus Anak-Anak dengan Ketunaandan Learning Disabilitas. Hikmah All Right reserved. Jakarta.

Kenyon, E., Beail, N., \& Jackson, T. (2014). Learning disability: experience of diagnosis. British Journal of Learning Disabilities, 42(4), 257-263.

Kementerian Kesehatan Republik Indonesia, (2014). Pedoman Pelayanan Kesehatan Anak Dengan Sisabilitas Bagi Keluarga. Kementerian Kesehatan Republik Indonesia. Jakarta.

Ohnston, T. C (2013). Self-concepts and socioemotional functioning of children with mild intellectual disability (MID) and parents' attributions for their children's academic struggles.

Paterson, L., McKenzie, K., \& Lindsay, B. (2012). Stigma, social comparison and self-esteem in adults with an intellectual disability. Journal of Applied Research in Intellectual Disabilities, 25(2), 166176.

Pijl, S. J., Skaalvik, E. M., \&Skaalvik, S. (2010). Student with special needs and the compositiom of their peer group. Irish Educational Studies, 29 (1), 57-70.

Rashid,N. (2012). Exclusion amongst muslim parents of mentally challenged children in hyderabad. Researchers World, 3(2), 25-32.

Romdhoni, M., (2013). Konsep Diri Siswa Tunagrahita Sedang Di Sekolah 
Luar Biasa Nurani Kota Cimahi. https://scholar.google.co.id/scholar? q.

Saban F, Arıkan D. The self-esteem and anxiety of children with and without mentally retarded siblings. J Res Med Sci 2013;18:961-9.

Sadock, B., \& Sadock, V. (2013).Concise Textbook Of Clinical Psychiatri. Ed. 2.Ahli bahasa; Profitasari \& Mahatmi. EGC. Jakarta.

Sadrossadat, L., Moghaddami, A., \& Sadrossadat, S. J. (2010). A comparison of adaptive behaviors among mentally retarded and normal individuals: A guide to prevention and treatment. International Journal of Preventive Medicine, 1

Sulistyarini, T., \& Saputra, Y. (2015). Dukungan Sosial Keluarga Pada Anak Retardasi Mental Sedang. Jurnal Stikes RS Baptis Kediri,8(2)

Vaz, S., Cordier, R., Falkmer, M., Ciccarelli, M., Parsons, R., McAuliffe, T., \&Falkmer, T. (2015). Should schools expect poor physical and mental health, social adjustment, and participation outcomes in students with disability? Plos One, 10(5)

Yeniarti, N. R., \& Mahmudah, S. (2015). Pengaruh penerapan bantuan tutor sebaya terhadap keterampilan memasak siswa tunagrahita ringan di SMP Negeri 4 Gresik Jawa Timur.

http://ejournal.unesa.ac.id/article/15 575/15/article.pdf

Zuna, N. I., Brown, I., \& Brown, R. I. (2014). Family quality of life in intellectual and developmental disabilities: A support-based framework. International Public Health Journal, 6(2), 161-184. 